\title{
CONCEPÇÕES DE PROFESSORES SOBRE IDENTIDADES JUVENIS NO CONTEXTO DAS REDES SOCIAIS VIRTUAIS
}

\author{
TEACHERS' CONCEPTIONS OF YOUTH IDENTITIES IN THE CONTEXT OF \\ VIRTUAL SOCIAL NETWORKS
}

DOI: $\underline{\text { 10.23926/RPD.2526-2149.2020.v5.n2.p1314-1328.id716 }}$

\author{
Douglas Pereira da \\ Costa \\ Mestre em Educação pela \\ Logos University \\ International (UNILOGOS) \\ douglascostapedagogo@hot \\ mail.com
}

\begin{abstract}
Resumo: Este artigo tem como objetivo discutir as concepções de cinco professores de Ensino Médio do Instituto Federal do Piauí sobre identidades juvenis no contexto das redes sociais virtuais. $\mathrm{O}$ estudo é de abordagem qualitativa e caráter descritivo. Os docentes foram entrevistados entre dezembro de 2017 e janeiro de 2018. As respostas desses sujeitos foram interpretadas pela Análise de Discurso. A forma como os professores entrevistados percebem os jovens no contexto das redes sociais enunciam uma perspectiva de juventude pluralizada e em constantes transformações. Permite detectar necessidades dos educandos nesse cenário, como orientações e espaços coletivos que propiciem conhecimentos sobre saúde emocional, diversidades, pensamento crítico e projeto de vida. Recomenda-se a abertura, por parte de profissionais da educação, ao diálogo com alunos e tecnologias, pois reconhecer as identidades subjetivas em percepções sensíveis é um ato educativo de caráter social para a docência na atualidade e para a formação integral dos educandos.
\end{abstract}

Palavras-chave: Concepções docentes. Identidades juvenis. Redes sociais virtuais. Jovens.

\begin{abstract}
This article aims to discuss the conceptions of five high school teachers at the Federal Institute of Piauí about youth identities in the context of virtual social networks. This is a study with a qualitative approach and descriptive character. Teachers were interviewed between December 2017 and January 2018. The responses of those participants were interpreted using Discourse Analysis. The way those teachers perceive and characterize young people in the context of social networks enunciate a perspective of pluralized youth that is in constant transformations. It allows the detection of students' needs in this scenario, such as guidelines and collective spaces that provide knowledge about emotional health, diversities, critical thinking, and life projects, among others. Education professionals should favor the dialogue with students and technologies. Therefore, recognizing subjective identities in sensitive perceptions is an educational act of a social nature for teaching today and for the students' holistic education.
\end{abstract}

Keywords: Teaching concepts. Youth identities. Virtual social networks. Young. 


\section{INTRODUÇÃO: CONECTANDO...}

Sobre o conto de Ruth Rocha (1986) acerca da escola de vidro, em que alunos eram enclausurados em vidros idênticos e que padronizavam suas identidades como se fossem seres iguais, pode-se refletir acerca das ações escolares que por muito tempo tentaram enquadrar e policiar sujeitos a comportamentos sociais opressores e de poda da liberdade subjetiva dos alunos.

No contexto das redes sociais virtuais, os possíveis vidros que instituições escolares ainda tentam manter intactos rompem-se de vez, pois os recursos midiáticos proporcionam maior mobilidade e fluidez na construção de identidades das novas gerações. Nesse cenário, as percepções subjetivas e socioculturais de educadores sobre as juventudes que transitam pelo ciberespaço tendem a influenciar na constituição dos processos educativos e formativos dos educandos, o que mobiliza a reflexão sobre a seguinte questão-problema: como docentes percebem as identidades de alunos jovens no contexto das redes sociais virtuais?

Nessa perspectiva, este estudo tem o objetivo de discutir as concepções de cinco professores de Ensino Médio integrado a cursos técnicos do Instituto Federal do Piauí, Campus Valença do Piauí (IFPI-CAVAL), sobre identidades juvenis no contexto das redes sociais virtuais. Os docentes participantes da pesquisa foram escolhidos por lecionarem em turmas nas quais, geralmente, os alunos são jovens compreendidos entre 15 e 17 anos de idade e familiarizados com o contexto das redes sociais virtuais. Assim sendo, os professores foram entrevistados no período de dezembro de 2017 a janeiro de 2018, e as respostas obtidas com as entrevistas foram interpretadas pela Análise de Discurso.

A pesquisa justifica-se pela carência de reflexões investigativas sobre essa temática, que emerge como relevante devido à necessidade de os professores de alunos jovens conhecerem as juventudes, suas realidades cada vez mais virtuais e o crescente protagonismo juvenil na cultura digital. Os conhecimentos docentes acerca dos alunos são de fundamental importância para o planejamento e execução de práticas educativas que mobilizem o desenvolvimento das competências, por parte dos educandos, propostas pela Base Nacional Comum Curricular (BNCC) para a Educação Básica. Inclusive, a primeira competência que o documento lista versa sobre a valorização e utilização dos mais variados conhecimentos da condição humana, dentre eles, os conhecimentos produzidos no/sobre o mundo digital, em paralelo à sua compreensão para subsidiar a construção social num viés de justiça, democracia e inclusão. Contudo, o maior compromisso das escolas é com a educação integral dos estudantes (BRASIL, 2018). 
O texto está organizado em partes. Inicialmente, apresenta uma reflexão teórica que aborda conexões temáticas em torno da constituição juvenil e o papel da escola na era digital. Em seguida, referencia a metodologia utilizada para a realização da pesquisa e, posteriormente, a análise dos dados e discussão dos resultados. Por fim, encerra com as considerações finais.

\section{CONEXões TeÓRICAS}

É perceptível a reconfiguração ocorrida nas sociedades por meio do fluxo tecnológico informacional, comunicativo e digital capaz de ocasionar uma distinção de eras na história social da humanidade, tendo em vista que o "[...] desenvolvimento das tecnologias de informação e comunicação é um elemento decisivo para criar marcas de tempo, consideradas igualmente um dos principais fatores de reconfiguração da sociedade" (BORTOLAZZO, 2012, p. 10).

$\mathrm{Na}$ Sociedade em Rede, marcada pelos efeitos fundamentais da tecnologia da informação no mundo contemporâneo, Castells (2017) sugere sociedade e tecnologia em um padrão interativo de relação, em que a sociedade incorpora e utiliza as inovações tecnológicas. Segundo a definição do autor, rede é o conjunto de nós interconectados. Para Recuero (2009), esses "nós" representam os atores, dentre os elementos das redes sociais, ou seja, pessoas espalhadas nos diversos pontos dos fluxos digitais e que "[...] atuam de forma a moldar as estruturas sociais, por meio da interação e da constituição de laços sociais" (RECUERO, 2009, p. 25).

Nesse aspecto, os jovens vivem cada vez mais conectados em redes sociais virtuais. De acordo com Palfrey e Gasser (2011, p. 29), para esses sujeitos, o ambiente digital é uma extensão do ambiente físico, onde simultaneamente comunicam suas identidades nos dois mundos (físico e digital). Contudo, os autores advertem: “A era da internet, em que estão crescendo os Nativos Digitais, está proporcionando outra grande mudança no que significa construir e administrar a própria identidade”. Em consonância, Castells (2017, p. 63) relata:

\footnotetext{
No entanto, a identidade está se tornando a principal e, às vezes, única fonte de significado em um período histórico caracterizado pela ampla desestruturação das organizações, deslegitimação das instituições, enfraquecimento de importantes movimentos sociais e expressões culturais efêmeras. Cada vez mais, as pessoas organizam seu significado não em torno do que fazem, mas com base no que elas são ou acreditam que são. Enquanto isso, as redes globais de intercâmbios instrumentais conectam e desconectam indivíduos, grupos, regiões e até países, de acordo com sua pertinência na realização dos objetivos processados na rede, em fluxo contínuo de decisões estratégicas. Segue-se uma divisão fundamental entre o instrumentalismo universal abstrato e as identidades particularistas historicamente enraizadas. Nossas sociedades estão cada vez mais estruturadas em uma oposição bipolar entre a Rede e o Ser.
} 
As novas gerações formam-se e delineiam seus modos de ser em um universo virtual instigado por novidades instantâneas, momentâneas e que se perfazem pelas conexões. Esses jovens possuem uma intensa afinidade com a gama de aparato tecnológico que surge diariamente, e, assim, os olhares educativos se voltam para essa categoria social que emerge em parâmetros diferenciados no século XXI. Presnky (2001) se apropria do termo "nativos digitais" para conceituar os jovens alunos que nascem e crescem em uma relação de proximidade com o mundo digital.

Bortolazzo (2012) aponta as marcas comuns às juventudes conectadas em mídias, tais como agilidade nas interpretações de imagens, realização de múltiplas tarefas ao mesmo tempo, facilidade na combinação de mídias, criatividade na personalização do que fazem, apreço pela liberdade, poder de escolha, inovações constantes e gosto pela diversão. Assim, os sujeitos juvenis lidam com a vida, seus problemas e prováveis responsabilidades de uma maneira diferenciada dos adultos.

A Base Nacional Comum Curricular (BNCC) explicita a atenção que deve ser dada à constituição dos jovens das novas gerações em meio ao universo informacional disponibilizado pelas mídias e pulverizadas pelas facilidades de acesso.

Há que se considerar, ainda, que a cultura digital tem promovido mudanças sociais significativas nas sociedades contemporâneas. Em decorrência do avanço e da multiplicação das tecnologias de informação e comunicação e do crescente acesso a elas pela maior disponibilidade de computadores, telefones celulares, tablets e afins, os estudantes estão dinamicamente inseridos nessa cultura, não somente como consumidores. Os jovens têm se engajado cada vez mais como protagonistas da cultura digital, envolvendo-se diretamente em novas formas de interação multimidiática e multimodal e de atuação social em rede, que se realizam de modo cada vez mais ágil. Por sua vez, essa cultura também apresenta forte apelo emocional e induz ao imediatismo de respostas e à efemeridade das informações, privilegiando análises superficiais e o uso de imagens e formas de expressão mais sintéticas, diferentes dos modos de dizer e argumentar característicos da vida escolar (BRASIL, 2018, p. 61).

Nesse sentido, diante da multiplicidade de ofertas midiáticas e digitais, as escolas são incumbidas do papel de formarem juventudes críticas, reflexivas, conscientes, responsáveis e que zelem pelo autocuidado (BRASIL, 2018). Dessa forma, os processos educativos precisam considerar a diversidade de realidades juvenis, inclusive, as emergentes das redes sociais virtuais. Afinal, a instituição escolar não é engessada em um único molde para todas as épocas, pelo contrário, cada momento exigirá dela justamente aquilo que é de necessidade para a sociedade, em suma, “[...] tem de ser repensada para responder aos desafios que a juventude nos coloca" (DAYRELL, 2007, p. 1107). 
Além do mais, o compromisso de educação integral para alunos de Educação Básica proposto pela BNCC compreende-se em um conjunto de competências que visam o desenvolvimento de conhecimentos, habilidades, atitudes e valores nas mais diversas dimensões do ser humano. Dentre elas, há as que se relacionam diretamente com a cultura digital. Há, também, as que tratam de conceitos mais subjetivos, tais como autoconhecimento, autocuidado e empatia (BRASIL, 2018).

Os professores precisam atentar para as multiplicidades de autorrepresentações jovens. Sujeitos sociais juvenis são singulares se comparados a outros, mas plurais em suas várias formas de manifestações identitárias pessoais e particulares. Dessa forma, no contexto fluido das tecnologias digitais, mais do que nunca, fortificam-se os princípios da pluralidade e diversidade humana.

\begin{abstract}
Nenhum ser humano é exatamente igual a outro - e isso se aplica tanto aos jovens quanto aos velhos. Contudo, é possível notar que, em determinadas categorias de seres humanos, algumas características ou atributos tendem a aparecer com maior frequência que em outras. É essa "condensação relativa" de traços característicos que nos permite falar, em primeiro lugar, em "categorias", sejam elas nações, classes, gêneros ou gerações. Ao fazê-lo, ignoramos temporariamente a multiplicidade de características que faz de cada um de seus integrantes uma entidade única e irrepetível, diferente de todas as outras, um ser que se destaca de todos os demais membros da "mesma categoria" (BAUMAN, 2011, p. 58, grifos do autor).
\end{abstract}

Adad (2014) elucida que não se pode reduzir a categoria social juvenil em uma definição permanente, concreta e estável, pois esta configura-se levando em consideração e tendo como ponto de partida os diversos tipos e estilos de culturas. Sobre esse prisma, Canevacci (2009) firma o conceito de multivíduo, apontando para a proliferação dos sujeitos relacionais nas metrópoles comunicacionais digitais.

Então, a cultura e a comunicação digital, que colocam em crise esta perspectiva coletiva, conseguem afirmar o processo conectivo que significa que a individualidade, que prefiro chamar de multivíduo, se multiplica, se amplia, explode. Uma multiplicidade de eus no corpo subjetivo. Essa condição múltipla favorece a proliferação dos eus o que acaba por desenvolver outro tipo de identidade, fluida e pluralizada, que coloca, potencialmente em crise, as formas perversas e tradicionais do dualismo (CANEVACCI, 2009, p. 9, grifos do autor).

No entanto, a escola não pode e não deve recriar vidros que enclausuram aos estudantes e seus corpos subjetivos, semelhantemente ao conto de Ruth Rocha (1986). Dessa forma, destaca-se a conexão dialógica como caminho para professores conhecerem as características que diferem as novas gerações, tendo em vista que as revoluções tecnológicas e a massificação da internet modificaram as formas de ser, agir, pensar, comportar-se e relacionar-se. Ao adentrar à escola, as composições de mundos dos alunos jovens, bem como de suas identidades 
produzidas fora dela, inserem-se no ambiente escolar, acompanhando e interferindo diretamente na trajetória formativa dos estudantes e nas relações interpessoais.

No ritmo das céleres composições virtuais, na maioria das vezes, não sobra espaço e tempo, por parte dos profissionais da educação, para o desenvolvimento de uma escuta sensível com os alunos. No entanto, as gerações atuais sentem necessidade de serem ouvidas, impondo à escola e aos professores que adotem uma postura de ouvintes. No instante em que isso acontece, efetiva-se o que Rubem Alves (2010) denomina de "escutatória", o aprendizado do ouvir. A partir dessa escuta sensível é possível perceber o conjunto de necessidades dos estudantes e desenvolver afeto, afeição e empatia com a condição juvenil. E ainda, compreender que

[...] eles são jovens, amam, sofrem, divertem-se, pensam a respeito das suas condições e de suas experiências de vida, posicionam-se diante dela, possuem desejos e propostas de melhorias de vida. Na trajetória de vida desses jovens, a dimensão simbólica e expressiva tem sido cada vez mais utilizada como forma de comunicação e de um posicionamento diante de si mesmos e da sociedade (DAYREEL, 2007, p. 1109).

É por meio da atenção à dimensão simbólica expressiva que professores poderão desenvolver suas percepções docentes acerca das identidades subjetivas juvenis. Recuero (2009) relata que os perfis de redes sociais são autorrepresentações dos sujeitos pertencentes a uma comunidade virtual. Dessa forma, o espaço digital configura-se em dimensão simbólica juvenil. Sendo assim, para os professores perceberem o impacto do universo virtual sobre a construção subjetiva, exige-se um treinamento constante em despir-se de visões historicamente construídas sobre as condições juvenis.

Conforme Dayrell (2007, p. 1108), tais condições dizem respeito "[...] ao modo como uma sociedade constitui e atribui significado a esse momento do ciclo da vida, no contexto de uma dimensão histórico-geracional". Por muito tempo, tentou-se enquadrar os jovens em categorias, das perspectivas românticas até as concepções reducionistas. Porém, para compreender a realidade própria da juventude atual, sem atrelar-se a uma linha romântica ou degradante, os professores precisam detectar os processos dinâmicos e socioculturais em sua volta e em torno dos alunos.

Treinar o olhar e se olhar, olhar-se. Porque não há nada de natural em olhar. O olhar é sempre culturalmente determinado. Então que olhar seja culturalmente determinado significa que agora, no contexto atual, a coisa mais significativa, seja didaticamente, seja fazendo pesquisa, é aprender, desenvolver, modificar, inventar, formas novas de olhar (CANEVACCI, 2009, p. 14). 
Em meio aos tempos fluidos e de relações sem solidez, além de dar voz aos diferentes sujeitos e ouvi-los, olhá-los e percebê-los torna-se fundamental para um processo educativo que vise o desenvolvimento pleno do educando. A essência está na potência do sentir. Professores precisam sentir os estudantes em meio aos agenciamentos de enunciações coletivas atuais. "A potência estética de sentir, embora igual em direito às outras - potências de pensar filosoficamente, de conhecer cientificamente, de agir politicamente -, talvez esteja em vias de ocupar uma posição privilegiada" (GUATARRI, 2012, p. 116).

No decorrer dos anos, os fatores e processos subjetivos tiveram importância. No entanto, ocupam lugar de evidência na atualidade e atuam fortemente no contexto das redes sociais, pois “[...] as máquinas tecnológicas de informação e de comunicação operam no núcleo da subjetividade humana, não apenas no seio de suas memórias, da sua inteligência, mas também da sua sensibilidade, dos seus afetos, dos seus fantasmas inconscientes" (GUATARRI, 2012, p. 14).

Nesse cenário, as instituições escolares precisam efetivar práticas pedagógicas que propiciem o desenvolvimento de todos os aspectos dos estudantes. Porém, os docentes devem perceber cada sujeito de aprendizagem em sua totalidade. Por isso, torna-se relevante discutir concepções de professores sobre identidades juvenis no contexto das redes sociais virtuais.

\section{Percurso Metodológico}

O estudo é de abordagem qualitativa e caráter descritivo, pois possui como objetivo discutir concepções de sujeitos sociais que situam-se em um determinado espaço (LUDWIG, 2014). Para conceder base empírica ao estudo, subsidiado por um roteiro com questões abertas e semiestruturadas, foram entrevistados cinco professores de Ensino Médio integrado a cursos técnicos do Instituto Federal do Piauí, Campus Valença do Piauí (IFPI-CAVAL).

Os docentes participantes da pesquisa foram escolhidos por lecionarem em turmas de Ensino Médio integrados a cursos técnicos, nas quais, geralmente, os alunos são jovens compreendidos entre 15 e 17 anos de idade e familiarizados com o contexto das redes sociais virtuais. Os entrevistados manifestaram pleno interesse em contribuir para a pesquisa ao assinarem o Termo de Consentimento Livre e Esclarecido (TCLE). Destaca-se que os professores serão referenciados no texto como: Professor A, Professor B, Professor C, Professor D e Professor E.

As entrevistas foram realizadas no período de dezembro de 2017 a janeiro de 2018. Essa técnica de coleta de dados corresponde aos anseios da pesquisa, pois 
[...] não significa uma conversa despretensiosa e neutra, uma vez que se insere como meio de coleta dos fatos relatados pelos atores, enquanto sujeitos-objeto da pesquisa que vivenciam uma determinada realidade que está sendo focalizada. Suas formas de realização podem ser de natureza individual e/ou coletiva. (MINAYO, 2001, p. 58).

Nessas condições, a interpretação das respostas obtidas nas entrevistas com os docentes em estudo foi realizada por meio da Análise de Discurso, de forma intuitiva, indutiva e descritiva, pois percebe-se que o discurso parte de um objeto sócio-histórico com ideologias externas a si, com uma linguagem, práticas cotidianas e que obedecem a relações de poder. Assim, “Analisar o discurso seria dar conta exatamente disso: de relações históricas, de práticas muito concretas, que estão 'vivas' nos discursos" (FISCHER, 2001, p. 198-199). Além disso, a discussão e análise dos dados é feita em paralelo a referenciais teóricos e legais sobre a temática abordada.

\section{CONCEPÇÕES DOS PROFESSORES SOBRE AS IDENTIDADES JUVENIS NO CONTEXTO DAS REDES SOCIAIS VIRTUAIS}

Segundo Fischer (2001), o discurso é formado por um conjunto de enunciados emanados de acontecimentos em determinados tempos e espaços e que, por sua vez, conjugam as formações discursivas por classes em um campo do saber. Entende-se que os professores do estudo emitem falas referentes ao campo do saber docente, experiencial, pedagógico, político e afins, que se relacionam com a temática em estudo. Dessa forma, os profissionais foram questionados sobre quais concepções possuem sobre jovens na atualidade, sobre identidades juvenis no contexto das redes sociais virtuais.

Professor A relata que existem diversas opiniões socialmente formuladas sobre as juventudes. Ele diz perceber os jovens na atualidade com muito mais espaço de liberdade para exposição de subjetividades e dos vários "eus" existentes em si. Considera espetacular a facilidade que possuem de serem várias pessoas ao mesmo tempo, exibindo isso e conseguindo dialogar com esses "eus". No entanto, ressalta que lhes falta capacidade de aceitar o confronto de uma sociedade conservadora composta por outras gerações, faltando-lhes estabilidade emocional para suportar as pressões sociais contrapostas aos modos que desejam viver. Quando isso acontece, tornam-se vulneráveis, desconstroem a si, correm risco de depressão e, algumas vezes, cometem suicídios.

Eu vejo esse jovem com a subjetividade que flui mais, tem mais facilidade de mostrar e exercitar prazerosamente, experimentar, mas que por conta da nossa incapacidade (sociedade) de aceitar essas subjetividades, ele não está ainda conseguindo confrontar com a realidade em que vive, e causa conflito, e a sociedade é isso, conflituosa (PROFESSOR A). 
Canevacci (2009, p. 9) conceitua essa multiplicidade de eus de multivíduo. Fruto da cultura e da comunicação digital, o conceito refere-se a um corpo subjetivo que se "[...] multiplica, se amplia e explode". A exposição em diversas redes sociais ao mesmo tempo, além de estar fisicamente em um lugar, enfatiza a natureza de um indivíduo único multiplicado em vários espaços simultaneamente. Em consonância, Palfrey e Gasser (2011, p. 9) vinculam os nativos digitais à experimentação de identidades múltiplas separadas e/ou convergidas. "Essa condição múltipla favorece a proliferação dos eus, o que acaba por desenvolver outro tipo de identidade, fluida e pluralizada, que coloca, potencialmente em crise, as formas perversas e tradicionais do dualismo".

No entanto, Professor A relata os confrontos entre a sociedade considerada como tradicional/conservadora e as identidades fluídas juvenis. Apesar das transformações sofridas pela sociedade, ainda há, por parte desta, uma rigidez quanto aos comportamentos considerados socialmente normais. Por outro lado, a liberdade jovem quer fluir livremente, mas encontra barreiras sólidas e não as sabe contornar. Os conflitos são gerados pelas diferenças entre gerações, inclusive, entre as gerações de professores e alunos. Diz o docente, “[...] nós fomos criados para sustentar muita coisa, em compensação nossa subjetividade era muito podada, não podia mostrar quem eu era, tinha que construir um eu ideal” (Professor A). Depreende-se que a solidez era um discurso teórico imposto sobre os sujeitos para uma efetivação prática de uma modelagem pessoal, mas na modernidade a sociedade é encaldeirada para os derretimentos desses sólidos (BAUMAN, 2001).

Ao estabelecer uma comparação entre a maneira que a formação do Professor A foi realizada e a necessidade das juventudes atuais de liberdade, nota-se mais do que uma diferenciação e reconhecimento das diferenças entre as gerações do docente e do alunado; isto é, percebe-se um exercício, por parte do professor, do treinamento de olhar os alunos e de olharse, expondo suas trajetórias e experiências na sua formação pessoal, social, educativa e subjetiva. Essa ação, na medida que é reflexiva e resulta em práticas intencionais, com objetivos educativos, torna-se uma prática docente (FRANCO, 2016). Mas sobre que prisma se dariam tais práticas? Sobre a necessidade de instruir jovens a lidar com as vulnerabilidades a que estão expostos no referido embate com a sociedade e, de outras maneiras, nas próprias mídias.

No fim do ano de 2016, ocorreu a morte de um garoto de 13 anos em uma "brincadeira" virtual em São Vicente, no estado de São Paulo (TARDIVO, 2016). Tais ocorrências são trágicas e mostram que debater e refletir sobre saúde mental nas escolas é essencial para orientar os jovens sobre o uso e a administração saudáveis das redes sociais e de suas identidades. Sendo 
assim, assuntos como depressão e suicídio, mencionados pelo Professor A, merecem discussões nos ambientes escolares, não para que a identidade jovem seja enclausurada, mas para que cada um possa "Conhecer-se, apreciar-se e cuidar de sua saúde física e emocional, compreendendose na diversidade humana e reconhecendo suas emoções e as dos outros, com autocrítica e capacidade para lidar com elas" (BRASIL, 2018, p. 10).

Para o Professor B, caracterizar os jovens nos dias de hoje "em isso ou aquilo" é desafiador, senão, impossível. O pensamento é justificado ao enfatizar as mudanças velozes e constantes pelas quais os jovens passam em um curto período, pois, na contemporaneidade, as diferenças entre as gerações acontecem em menor espaço de tempo. Além disso, a definição de jovem, em sua opinião, também é construída no seio da família.

Passa muito pela questão da família também, esse definir o que seria o jovem. O
professor tem a sua participação, mas eu acredito muito no poder dos pais, da base,
na constituição desse jovem, a partir da experiência que ele tem com os pais, vai levar
isso pra sua vida pessoal, pra construir sua própria história, aí a formação família e
escola vai moldar o jovem, até na hora de fazer um post na internet, "ah meus pais
vão ver, eles têm acesso à rede também", isso vai da realidade também de cada jovem,
tem uns mais liberais, outros são mais acomodados, e aí o reflexo disso, até sobre o
uso das redes sociais, quando a família é muito liberal, também fazem a vontade, sem
pensar no que possa acontecer (PROFESSOR B).

É possível associar a missão desafiadora de classificação da categoria juvenil presente na introdução discursiva do Professor B ao posicionamento de Dayrell (2003). O autor esclarece a dificuldade de construir uma definição, pois os critérios adotados na análise constituinte juvenil são históricos e culturais, e isso interliga-se ao expressado pelo docente sobre as mudanças aceleradas que vigoram no presente. Em se tratando de cultura digital, a efemeridade é ainda mais latente, pois os aspectos que as solidificariam alteram-se instantaneamente. $\mathrm{Na}$ verdade, essa pode ser a característica que maior diferencia a constituição dessa identidade cultural.

No contexto em que é comum jovens exibirem suas identidades on-line, é de responsabilidade dos familiares, não somente da escola, a preocupação com os riscos indiciados sobre a formação da identidade juvenil (PALFREY; GASSER, 2011). No entanto, as famílias também estão em um processo de adequação a uma sociedade digital, de modo que não conseguem manter os sujeitos em total segurança. Pais (2005) introduz a internet como uma porta de entrada ao refúgio enclausurador e protecionista caseiro, que rompe o "casulo familiar" e finda por outorgar poderes aos jovens de consumirem novas culturas.

Nessas circunstâncias, a escola assume função socioeducativa 
[...] em relação à formação das novas gerações. É importante que a instituição escolar preserve seu compromisso de estimular a reflexão e a análise aprofundada e contribua para o desenvolvimento, no estudante, de uma atitude crítica em relação ao conteúdo e à multiplicidade de ofertas midiáticas e digitais. (BRASIL, 2018, p. 61).

$\mathrm{Na}$ concepção do Professor $\mathrm{C}$, os jovens são ansiosos, acelerados, impacientes, imediatistas, querem "tudo pra ontem" e extremamente curiosos. Essa curiosidade "leva a juventude além", em vários sentidos. Conforme Prensky (2001, p. 2), as primeiras gerações de nativos digitais possuem essas características de praticidade e instantaneidade, bem como “[...] trabalham melhor quando ligados a uma rede de contatos. Eles têm sucesso com gratificações instantâneas e recompensas freqüentes. Eles preferem jogos a trabalham 'sério'. (Isto lhe parece familiar?)”. Ou ainda, de acordo com Bortolazzo (2012), a geração digital é frenética.

Dentre a forma como o Professor D define as juventudes, destaca as novas gerações como sonhadoras, uma vez que

\footnotetext{
Pensar a juventude é também pensar sobre nós mesmos, seja o nosso presente, ou passado recente. O jovem é sinônimo de construção, busca, planos, processo. Uma fase peculiar onde os sonhos e desejos estão todos voltados para as conquistas, os empreendimentos. Assim se canalizam as energias para a luta, a garra. Nesse sentido, muda-se o tempo, mas a juventude em si, na sua essência é a mesma, com desejos e vontades de realização, seja de terminar os estudos, conseguir o emprego dos sonhos e até mesmo constituir família (PROFESSOR D).
}

O modo de pensar juventude, impresso pelo discurso docente acima, baliza uma fundamentação em duas direções. A primeira diz respeito à essência da juventude mantida historicamente, justificada pela força sonhadora dessa categoria em todas as gerações. Mas que, na segunda, ao tomar os jovens como estáticos, ou seja, imutáveis em uma linha histórica de comparações em tempos passados e o presente, foge do direcionamento dado pelas teorias já acrescidas no estudo, como a de Dayrell (2007), adepto à existência do universo simbólico próprio do ser juvenil que o diferencia das gerações anteriores.

Todavia, não é possível considerar que o Professor D esteja errado. Pois, devido à condição pluralizada que os jovens possuem e que resulta em juventudes (no plural), há múltiplas formas de visualizá-los, uma vez que os lugares sociais e aspectos culturais são determinantes nas expressões e constituições juvenis (DAYRELL, 2003). Dessa forma, no espaço das redes sociais virtuais não seria diferente, por ser um lugar comum de exposição e manifestação de desejos dos jovens, e assim, de diversidades transversais a todas as formas de produção identitária que se envolvem no universo digital. Nesse contexto, as instituições escolares necessitam dialogar sobre diversidades e pluralidades.

Ao dizer que pensar as juventudes “é pensar sobre nós”, Professor D busca semelhanças entre as gerações, concluindo que há uma essência sonhadora que os aproxima. No entanto, no 
processo educativo é fundamental reconhecer as diferenças como um princípio construtivo de si e do outro, não preconceituosamente, mas como manifestação de respeito ao lugar social do outro. Por essa razão, conforme a BNCC, o aluno precisa desenvolver a competência relacionada ao exercício da empatia, “[...] o diálogo, a resolução de conflitos e a cooperação, fazendo-se respeitar e promovendo o respeito ao outro e aos direitos humanos, com acolhimento e valorização da diversidade de indivíduos e de grupos sociais, seus saberes, identidades, culturas e potencialidades, sem preconceitos de qualquer natureza." (BRASIL, 2018, p. 9).

Duas visões são concebidas pelo Professor E sobre os jovens:

1. Uma "visão geral", que são pessoas cheias de sonhos, porém que pouco fazem para alcançá-los.

2. É ser atualizado com as diferentes situações que acontecem no mundo. (PROFESSOR E).

Apesar de o Professor E concordar com o Professor D a respeito da perspectiva juvenil sonhadora, diz que os jovens pouco esforçam-se para realizarem os sonhos. A segunda proposição elaborada pelo professor acarreta sobre si a admissão de que esses sujeitos, de maneira aligeirada e por processos digitais, adquirem informações com mais habilidade do que os adultos e professores. Essa realidade é comentada por Presnky (2001), as escolas não possuem exclusividade sobre a detenção de informações e muitas fontes de conhecimentos estão disponíveis nas mídias digitais. Nessa perspectiva, o professor torna-se um mediador na formação crítica dos alunos mediante os conteúdos multimidiáticos e digitais.

Nesse contexto, o professor é incentivado a tornar-se um animador da inteligência coletiva de seus grupos de alunos em vez de um fornecedor direto de conhecimentos. [...] Se as pessoas aprendem com suas atividades sociais e profissionais, se a escola e a universidade perdem progressivamente o monopólio da criação e transmissão do conhecimento, os sistemas públicos de educação podem ao menos tomar para si a nova missão de orientar os percursos individuais no saber e de contribuir para o reconhecimento dos conjuntos de saberes pertencentes às pessoas, aí incluídos os saberes não acadêmicos. (LÉVY, 2010, p. 160).

De acordo com o Professor E, os jovens estão constantemente atualizados sobre informações globais devido ao acesso às redes sociais. Lévy (2010) propõe a aprendizagem personalizada e a necessidade de reconhecimento dos conhecimentos adquiridos com as experiências extraescolares vivenciadas em outros locais ou advindas de outros meios, a exemplo das redes sociais. Isso converge-se para a orientação de alunos na construção dos seus projetos de vidas.

Valorizar a diversidade de saberes e vivências culturais e apropriar-se de conhecimentos e experiências que lhe possibilitem entender as relações próprias do mundo do trabalho e fazer escolhas alinhadas ao exercício da cidadania e ao seu 
projeto de vida, com liberdade, autonomia, consciência crítica e responsabilidade. (BRASIL, 2018, p. 9).

De maneira geral, ao analisar os enunciados dos professores, nota-se um discurso polifônico, pois por mais que sejam harmoniosos, em alguns momentos, notou-se um destoar discursivo justificado pelo próprio sentido múltiplo da condição juvenil. No entanto, pode-se considerar positivamente as percepções múltiplas dos professores entrevistados sobre as identidades juvenis, pois demonstra-se que não há um rótulo pré-definido nas falas referentes ao campo do saber docente, experiencial, pedagógico, político e afins entre os profissionais da instituição campo da pesquisa.

\section{CONSIDERAÇões FinAIS}

Em meio ao campo teórico e empírico, destaca-se como de suma importância professores conhecerem as novas gerações de alunos digitais, visando a uma relação interpessoal, pedagógica e educativa eficaz. Somente através de um conhecimento desmistificado, sem rotulações prévias, que professores serão capazes de articular as redes sociais virtuais ao processo de ensino e aprendizagem e ao desenvolvimento pessoal, identitário e subjetivo do alunado, cada dia mais contextualizado com as novas tecnologias digitais de informação e comunicação.

A forma como os professores entrevistados percebem e caracterizam os alunos no contexto das redes sociais virtuais permite detectar algumas necessidades dos educandos nesse cenário, tais como a de orientações e espaços coletivos que propiciem conhecimentos sobre saúde emocional, diversidades, pensamento crítico, projeto de vida, dentre outros. Evidenciase que é permitindo-se atentar para as dimensões simbólicas juvenis que as instituições escolares podem contribuir para a formação integral dos educandos.

Ressalta-se que este estudo não pretende classificar ou reduzir as condições juvenis às concepções emitidas pelos docentes participantes. No entanto, tais percepções enunciam a perspectiva de juventude pluralizada, múltipla e em constantes transformações. Indicam uma fluidez e mobilidade nas transições de identidades. Essa realidade é capaz de nortear o fazer pedagógico para jovens heterógenos, que não aprendem e nem se relacionam de maneira homogênea, dando maior espaço à liberdade subjetiva numa linguagem nativa digital e emergida em traços da cultura digital.

Recomenda-se a abertura, por parte de profissionais da educação, ao diálogo com alunos e tecnologias, pois percebe-se que os nativos digitais precisam de orientações para a administração de suas identidades nas comunidades virtuais e na transição entre os mundos 
físico, social, cultural e digital. Dessa forma, a escola deve buscar estratégias capazes de desenvolver competências para o uso crítico, significativo, reflexivo e ético das tecnologias de comunicação e informação pelas juventudes.

Portanto, a escola não pode fugir de mais uma responsabilidade que lhe é imposta devido ao contexto atual tecnológico e digital. E, assim, olhar, ouvir e sentir são ações inerentes aos sentidos e capacidades humanas. Dessa forma, conhecer e reconhecer as identidades subjetivas em percepções sensíveis é um ato educativo de caráter prático e social para a docência na atualidade e para a formação integral dos educandos.

\section{REFERÊNCIAS}

ADAD, Shara Jane Holanda Costa. Juventudes e corpos na educação contemporânea. In: BOMFIM, Maria do Carmo Alves do; ADAD, Shara Jane Holanda Costa; NASCIMENTO, Adriana Loiola do (Org.). Educação, diversidades e políticas de inclusão: juventudes, cultura de paz e subjetividades. v. 2. Teresina: EDUFPI, 2014. p. 41-47.

ALVES, Rubem. Educação dos sentidos e mais... Campinas, São Paulo: Verus Editora, 2010 .

BAUMAN, Zygmunt. 44 Cartas do Mundo Líquido Moderno. Rio de Janeiro: Zahar, 2011.

BAUMAN, Zygmunt. Modernidade líquida. Tradução Plínio Dentzien. Rio de Janeiro: Zahar, 2001.

BORTOLAZZO, Sandro Faccin. Nascidos na era digital: outros sujeitos, outra geração. In: ENCONTRO NACIONAL DE DIDÁTICA E PRÁTICAS DE ENSINO (ENDIPE), 16, 2012, Campinas. Anais... Campinas: Junqueira\&Marin Editores, 2012. p. 2-13.

BRASIL. Base Nacional Comum Curricular. Ministério da Educação. Brasília, 14 de dezembro de 2018. Disponível em:

http://basenacionalcomum.mec.gov.br/images/BNCC_EI_EF_110518_versaofinal_site.pdf.

Acesso em: 10 jan. 2019.

CANEVACCI, Massimo. A comunicação entre corpos e metrópoles. Revista signos do consumo, São Paulo, v. 1, n. 1, p. 8-20, abr. 2009. Disponível em: https://doi.org/10.11606/issn.1984-5057.v1i1p8-20. Acesso em: 20 fev. 2018.

CASTELLS, Manuel. A sociedade em rede. 18. ed. São Paulo: Paz e Terra, 2017.

DAYRELL, Juarez. A escola "faz" as juventudes? Reflexões em torno da socialização juvenil. Educação e sociedade, Campinas, v. 28, n. 100, p. 1105-1128, out. 2007. Disponível em: https://doi.org/10.1590/S0101-73302007000300022. Acesso em: 12 out. 2017.

DAYRELL, Juarez. O jovem como sujeito social. Revista brasileira de educação, Rio de Janeiro, n. 24, p. 44-52, dez. 2003. Disponível em: https://doi.org/10.1590/S141324782003000300004. Acesso em: 12 out. 2017. 
FISCHER, Rosa Maria Bueno. Foucault e a análise do discurso em educação. Cadernos de pesquisa, São Paulo, n. 114, p. 197-223, nov. 2001. Disponível em:

https://doi.org/10.1590/S0100-15742001000300009. Acesso em: 18 dez. 2017

FRANCO, Maria Amélia do Rosario Santoro. Prática pedagógica e docência: um olhar a partir da epistemologia do conceito. Revista brasileira de estudos pedagógicos, Brasília, v. 97, n. 247, p. 534-551, set./dez. 2016. Disponível em: https://doi.org/10.1590/s21766681/288236353. Acesso em: 12 maio 2020.

GUATARRI, Félix. Caosmose: um novo paradigma estético. 2. ed. Rio de Janeiro: Editora 34, 2012.

LÉVY, Pierre. Cibercultura. 3. ed. São Paulo, Editora 34, 2010.

LUDWIG, Antonio Carlos Will. Métodos de pesquisa em educação. Revista temas em educação, João Pessoa, v. 23, n. 2, p. 204-233, jul./dez. 2014. Disponível em:

https://periodicos.ufpb.br/ojs/index.php/rteo/article/view/18881/12572 Acesso em: 12 maio 2020.

MINAYO, Maria Cecília de Souza. Pesquisa social. teoria, método e criatividade. 18. ed. Petrópolis: Vozes, 2001.

PAIS, José Machado. Jovens e Cidadania. Sociologia, problemas e práticas, Lisboa, v. 1, n. 49, p. 53-70, fev. 2005.

PALFREY, John; GASSER, Urs. Nascidos na era digital: entendendo a primeira geração de nativos digitais. Porto Alegre: Artmed, 2011.

PRENSKY, Marc. Nativos Digitais, Imigrantes Digitais. Tradução Roberta de Moraes Jesus de Souza. On the Horizon, Oxford, v. 9. n. 5, p. 1-6, jan. 2001.

RECUERO, Raquel. Redes sociais na internet. Porto Alegre: Sulina, 2009.

ROCHA, Ruth. Quando a escola é de vidro. Rio de Janeiro: Salamandra, 1986.

TARDIVO, Cassiana. Os filhos do quarto. Sergipe: Colégio Americano Batista, 2016. Disponível em: http://colegioamericanobatista.com.br/2016/11/04/os-filhos-do-quarto/ Acesso em: 15 jun. 2017.

Recebido em: 24 de maio de 2020.

Aprovado em: 30 de agosto de 2020. 